\title{
Automatic monitoring of the effective thermal conductivity of snow in a low-Arctic shrub tundra
}

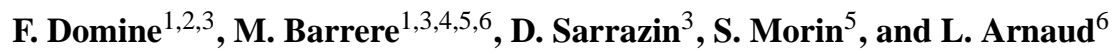 \\ ${ }^{1}$ Takuvik Joint International Laboratory, Université Laval (Canada) and CNRS-INSU (France), Pavillon Alexandre Vachon, \\ 1045 avenue de La Médecine, Québec, QC, G1V 0A6, Canada \\ ${ }^{2}$ Department of Chemistry, Université Laval, Québec, QC, Canada \\ ${ }^{3}$ Centre for Northern Studies, Université Laval, Québec, QC, Canada \\ ${ }^{4}$ Department of Geography, Université Laval, Québec, QC, Canada \\ ${ }^{5}$ Météo-France - CNRS, CNRM-GAME UMR 3589, CEN, Grenoble, France \\ ${ }^{6}$ LGGE, Université Grenoble Alpes and CNRS - UMR5183, 38041 Grenoble, France \\ Correspondence to: F. Domine (florent.domine@gmail.com)
}

Received: 28 January 2015 - Published in The Cryosphere Discuss.: 13 March 2015

Revised: 10 May 2015 - Accepted: 31 May 2015 - Published: 22 June 2015

\begin{abstract}
The effective thermal conductivity of snow, $k_{\text {eff }}$, is a critical variable which determines the temperature gradient in the snowpack and heat exchanges between the ground and the atmosphere through the snow. Its accurate knowledge is therefore required to simulate snow metamorphism, the ground thermal regime, permafrost stability, nutrient recycling and vegetation growth. Yet, few data are available on the seasonal evolution of snow thermal conductivity in the Arctic. We have deployed heated needle probes on low-Arctic shrub tundra near Umiujaq, Quebec, (N56 $34^{\prime}$; $\mathrm{W} 76^{\circ} 29^{\prime}$ ) and monitored automatically the evolution of $k_{\text {eff }}$ for two consecutive winters, 2012-2013 and 2013-2014, at four heights in the snowpack. Shrubs are $20 \mathrm{~cm}$ high dwarf birch. Here, we develop an algorithm for the automatic determination of $k_{\text {eff }}$ from the heating curves and obtain 404 $k_{\text {eff }}$ values. We evaluate possible errors and biases associated with the use of the heated needles. The time evolution of $k_{\text {eff }}$ is very different for both winters. This is explained by comparing the meteorological conditions in both winters, which induced different conditions for snow metamorphism. In particular, important melting events in the second year increased snow hardness, impeding subsequent densification and increase in thermal conductivity. We conclude that shrubs have very important impacts on snow physical evolution: (1) shrubs absorb light and facilitate snow melt under intense radiation; (2) the dense twig network of dwarf birch
\end{abstract}

prevent snow compaction, and therefore $k_{\text {eff }}$ increase; (3) the low density depth hoar that forms within shrubs collapsed in late winter, leaving a void that was not filled by snow.

\section{Introduction}

Snow on the ground acts as a thermally insulating layer which limits ground cooling in winter. This has large scale and far-reaching implications concerning for example the recycling of soil nutrients and their availability for the subsequent growing season (Saccone et al., 2013; Sturm et al., 2005) and the thermal regime of permafrost (Zhang, 2005). An essential variable to quantify snow thermal effects is its effective thermal conductivity, $k_{\text {eff }}$ (Calonne et al., 2011; Sturm et al., 1997), defined as

$F=-k_{\text {eff }} \frac{\mathrm{d} T}{\mathrm{~d} z}$

with $F$ the heat flux in $\mathrm{W} \mathrm{m}^{-2}$ and $\mathrm{d} T / \mathrm{d} z$ the vertical temperature gradient in $\mathrm{K} \mathrm{m}^{-1}$ through the layer. The variable is termed "effective" because besides the fact that it is meant to represent the conductive behavior of snow as a porous medium made of ice and air, which already makes it an effective property, it also implicitly includes processes such as heat transfer by latent heat exchanges caused by sublimation 
and condensation during snow metamorphism (Sturm et al., 1997).

The snowpack is made up of layers of different properties, and the insulating properties of a whole snowpack may be described by its thermal resistance $R_{\mathrm{T}}$ (Domine et al., 2012; Liston et al., 2002; Sturm et al., 2001), which sums up the properties of all the layers:

$R_{\mathrm{T}}=\sum_{i} \frac{h_{i}}{k_{\mathrm{eff}, i}}$,

where $h_{i}$ is the thickness of layer $i . R_{\mathrm{T}}$ thus has units of $\mathrm{m}^{2} \mathrm{~K} \mathrm{~W}^{-1}$. Under steady-state conditions, this variable relates the upward heat flux through the snowpack $F$ to the temperature difference between its surface and its base, $T_{\text {top }}-T_{\text {base }}$ :

$F=-\frac{T_{\text {top }}-T_{\text {base }}}{R_{\mathrm{T}}}$.

However, while $R_{\mathrm{T}}$ gives a useful and intuitive indication of the snowpack properties, representing a complex layered snowpack as a single homogeneous layer characterized by $R_{\mathrm{T}}$ can lead to very large errors in simulated soil temperature, because steady-state conditions are seldom reached in nature. The detailed thermal structure of the snowpack must therefore be known for a proper simulation of the ground thermal regime (Ekici et al., 2014), and how it will evolve with global warming.

Sturm et al. (2005) and Gouttevin et al. (2012) have shown that snow-vegetation interactions could accelerate permafrost thawing in a climate warming context. The general idea is that warming-induced shrub growth on Arctic herb tundra leads to snow trapping. Shrubs then shelter snow from wind erosion and compaction, facilitating the formation of insulating depth hoar layers at the expense of more heat-conductive wind slabs. This results in reduced soil winter cooling. Gouttevin et al. (2012) illustrated the effect of vegetation by examining the extreme case where herb tundra would be replaced by taiga. $R_{\mathrm{T}}$ values increase from about $3 \mathrm{~m}^{2} \mathrm{~K} \mathrm{~W}^{-1}$ for herb tundra to values at least 4 times higher for taiga, resulting in soil warming reaching $12 \mathrm{~K}$. Since permafrost thawing could lead to the microbial mineralization of soil carbon, with the release of greenhouse gases $\mathrm{CO}_{2}$ and $\mathrm{CH}_{4}$ (Koven et al., 2011; Schuur et al., 2008), this example demonstrates the importance of snow-vegetation interactions to understand snow thermal conductivity and the ground thermal regime.

Improving the description of thermal conductivity in snow and land surface models requires, in addition to model improvements, the acquisition of in situ data in various environments. In particular, very little data are available on the thermal conductivity of Arctic and subarctic snow as it evolves through the winter, especially as a function of vegetation type. Indeed, interactions between snow and vegetation are believed to play a strong role on the time evolution of the physical properties of snow (Liston et al., 2002). Winter-long monitoring of snow thermal conductivity has rarely been done, and these few studies are limited to taiga (Sturm and Johnson, 1992) and Alpine snow (Morin et al., 2010).

The purpose of this work is twofold. First, we test a method for the continuous monitoring of snow thermal conductivity in northern regions and for the automatic analysis of the data. Second, we obtain 2 years of data on the evolution of snow thermal conductivity, and these are the first such time series for snow on shrub tundra. We therefore discuss these data and in particular two aspects where the new time series differ from existing ones: the impact of shrubs and of melt-freeze events on the evolution of $k_{\text {eff }}$.

\section{General methods}

Our study site was near Umiujaq, on the eastern shore of Hudson Bay, Quebec, Canada, 56 $33^{\prime} 31^{\prime \prime} \mathrm{N}, 76^{\circ} 28^{\prime} 56^{\prime \prime} \mathrm{W}$. Vegetation types there include herb tundra, shrub tundra with dwarf birch and willows, $20 \mathrm{~cm}$ to $1 \mathrm{~m}$ height, and forest tundra (i.e. forest patches on tundra (Payette et al., 2001). Bare basalt outcrops are also frequent. Umiujaq is just north of the tree line, as the boreal open forest can be found about $40 \mathrm{~km}$ to the east and south. The experimental system discussed here was deployed in shrub tundra dominated by dwarf birch (Betula glandulosa). The ground under the birch was entirely covered with cladonia, a thick ( $\approx 5$ to $10 \mathrm{~cm}$ ) white lichen of very low density that formed a highly insulating layer on top of the ground. Measured $k_{\text {eff }}$ valued in the cladonia were around $0.025 \mathrm{~W} \mathrm{~m}^{-1} \mathrm{~K}^{-1}$, essentially the value of air. The system deployed consisted of four TP02 heated needle probes (NPs) from Hukseflux, fixed horizontally in holes drilled in vertical poles at heights $14,24,34$ and $44 \mathrm{~cm}$, measured from the base of the lichen in August 2012. These heights were selected to focus on the impact of shrubs on snow properties. In August 2012, the dwarf birch at the study site were $20 \mathrm{~cm}$ high at most. In October 2014, the shrubs had grown to 30 to $35 \mathrm{~cm}$ high (Fig. 1). The heights cannot be determined with a precision better than $4 \mathrm{~cm}$. Because of the continuum between lichen and litter, the vegetationground interface cannot be located accurately. In fact, heights measured in October 2014 were $3 \mathrm{~cm}$ less. Pt1000 temperature sensors are integrated into the base of each probe. The pole supporting the NPs were placed in August 2012. Due to logistical difficulties, the NPs were not available at that time and they were inserted on 14 February 2013. A block of snow was carefully removed, the probes were inserted horizontally and the block was rapidly replaced, with minimal perturbation to the snowpack. Measurements were started on 16 February 2013 until the end of the snow season in late April, and a second winter of measurements was recorded for the whole 2013-2014 winter.

The heated NP method has been discussed in detail by Sturm and Johnson (1992) and Morin et al. (2010). Briefly, 


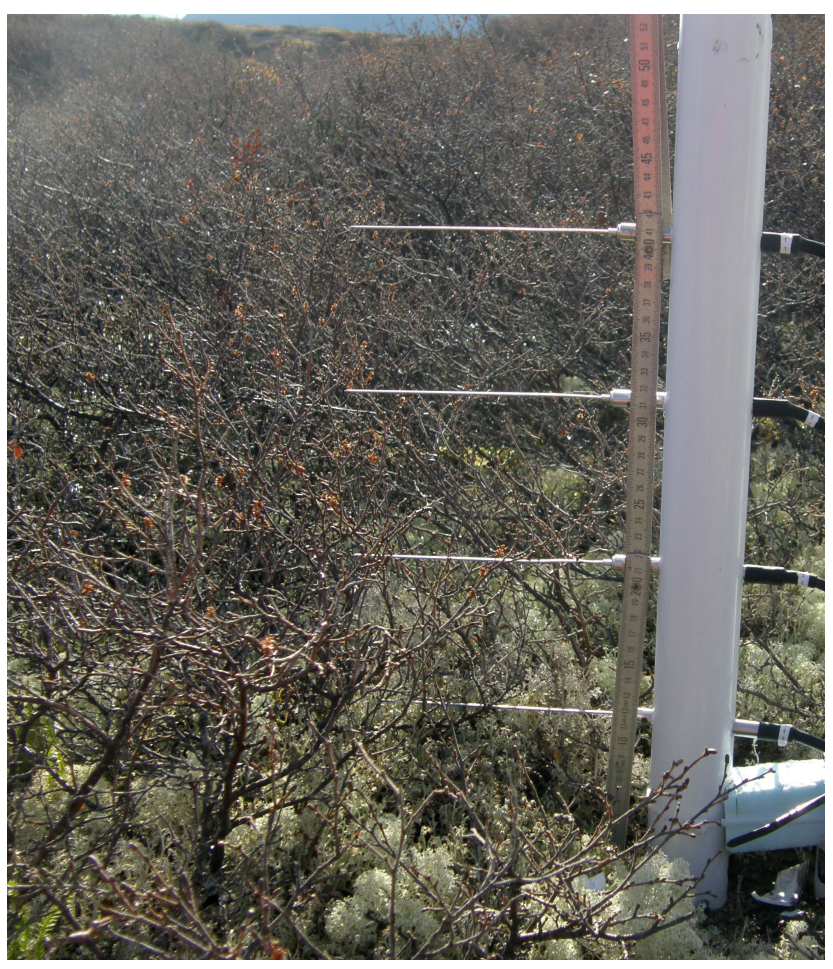

Figure 1. Photograph of the four TP02 needle probes deployed in shrub tundra. The photo was taken on 6 October 2014, when the dwarf birch had grown to about $30 \mathrm{~cm}$ high. The needle probes are $14,24,34$ and $44 \mathrm{~cm}$ above the ground-lichen interface.

the needle comprises a $10 \mathrm{~cm}$ heated zone, which is heated at constant power $\left(q=0.4 \mathrm{~W} \mathrm{~m}^{-1}\right)$. The temperature is monitored at the center of the heated zone. Heat dissipation depends on the effective thermal conductivity of the medium. By plotting the temperature of a thermocouple located at the center of the needle heated zone as a function of $\ln (t)$, where $t$ is time, a linear curve is theoretically obtained, whose slope is inversely proportional to $k_{\text {eff. }}$.

Besides conductive and latent heat exchange processes, air convection in the snowpack can contribute to heat transfer (Sturm et al., 1997). Convection in snow is not an intrinsic property of the snow, as it depends among other factors on the temperature gradient in the snow, so our data analysis will need to detect its possible occurrence and avoid resulting perturbations in the measurement of $k_{\text {eff }}$.

Thermal conductivity in snow is often anisotropic (Calonne et al., 2011) with the vertical component either greater or smaller than the horizontal one depending on snow type. Horizontal NPs therefore measure a mixture of both components while the relevant variable for soil to atmosphere heat transfer is the vertical component. The impact of this aspect will be addressed in the discussion section.

The heating time used was $150 \mathrm{~s}$. A temperature reading was recorded every second during heating, and every second for $150 \mathrm{~s}$ during the subsequent cooling stage. The vari- able $k_{\text {eff }}$ can be independently determined from the heating and cooling curves, but using the heating curve gives more accurate values (Morin et al., 2010; Sturm and Johnson, 1992), so that using the cooling curve did not improve the determination of $k_{\text {eff. }}$. Our work therefore focused on treating the heating curve. Our setup and methods are similar to those of Morin et al. (2010), who estimate the accuracy of the measurement to be better than $5 \%$ or $0.005 \mathrm{~W} \mathrm{~m}^{-1} \mathrm{~K}^{-1}$, whichever is larger.

The TP02 probes were automated by a Campbell Scientific CR1000 data logger, powered by batteries and a solar panel. Since snow thermal conductivity evolved fairly slowly, a measurement was performed every 2 days at 05:00, when the air temperature was lowest to minimize the risk of melting. This frequency of measurement minimizes perturbation to the snow's natural evolution caused by the heating: typically, the temperature rises by about $1{ }^{\circ} \mathrm{C}$ for less than one minute every other day, totalling about 90 min of very moderate heating during the whole winter. For each probe, the data logger program verified that the snow temperature was below $-2.0^{\circ} \mathrm{C}$ before starting the heating cycle. This was to avoid snow melting, which would have irreversibly perturbed the snow structure.

Even though heating curves are in principle linear, many perturbations can take place, resulting in parts of the plots that are curved so that a time range must be selected to derive $k_{\text {eff }}$. Given the amount of data obtained, manually selecting the correct interval can be very time consuming and an automated procedure was sought. An important objective of this work is to validate this automatic procedure, so that it can be applied reliably to other similar systems that are being deployed in the Arctic.

In addition to snow thermal conductivity, we also deployed many instruments to monitor environmental variables required to simulate the evolution of snow physical properties. Measurements were recorded hourly. These included an air temperature and relative humidity sensor model HC2S3 from Rotronic, a cup anemometer, both at $2.3 \mathrm{~m}$ height, a SR50A acoustic snow height gauge, a CNR4 radiometer from Kipp $\&$ Zonen that measured downwelling and upwelling shortwave and longwave radiation. The radiometer was ventilated with a CNF4 heated fan to reduce the risk of frost build up and snow accumulation. The CNF4 was operated $5 \mathrm{~min}$ every hour just before the hourly measurements. Likewise, the $\mathrm{HC} 2 \mathrm{~S} 3$ sensor was placed in white ventilated U-shaped tubing whose fan was run for 5 min before measurement. Furthermore, thermistors were placed in the snow at heights above ground of $0,4,8,16,24,30$ and $38 \mathrm{~cm}$.

In addition to automatic measurements, field measurements were done in February 2013 and January and February 2014. Each time, 10 to 15 snow pits were dug to investigate snow spatial variability. The stratigraphy was examined and profiles of density and thermal conductivity were measured. Snow density was measured with a $100 \mathrm{~cm}^{3}$ box cutter (Conger and McClung, 2009) and a field scale. This proved 
difficult when ice layers were present, as breaking ice layers cleanly is delicate. We estimate than when thick ice layers were present, density underestimates of about $20 \%$ were possible, but the exact error in this case is very difficult to evaluate.

\section{Treatment of the heating curves}

The treatment of the heating curves has been detailed in Sturm and Johnson (1992) and Morin et al. (2010). Ideally, after an initiation period of about $20 \mathrm{~s}$ where the "linear" equation does not apply, the heating curves obtained with the NP method should be linear (with a logarithmic scale for time) and the thermal conductivity extracted from any time interval should yield a unique value, assuming that the needle is in perfect thermal contact with the medium which is further assumed to be homogeneous (Morin et al., 2010). Riche and Schneebeli (2010) have raised the issue of the imperfect contact between the needle and the snow, caused by damage to the snow during needle insertion, which modifies thermal conductivity around the needle. However, the impact of such effects are generally limited to short heating times as demonstrated by Morin et al. (2010), which corresponds to the period of time which needs to be discarded from the analysis anyway. Furthermore, in our case the needles are left in place and are not inserted for each measurement. As a result, the snow structure forms and evolves around the needle, and there is no perturbation caused by the insertion. In most cases, apart from the initial period of about $20 \mathrm{~s}$, the heating curves are linear as shown in Fig. 2a.

In low density snow with large grains such as depth hoar, plots can be curved at long heating times, as shown in Fig. 2b. Sturm and Johnson (1992) attribute this change of slope to the onset of convection, which by adding an extra heat transfer process, reduces the needle heating rate. Since we are interested in conductive and latent heat transfer processes only, the correct value for us is obviously that of the steepest part of the plot after the initiation period, here between 20 and $50 \mathrm{~s}$, which gives a $k_{\text {eff }}$ value of $0.053 \mathrm{~W} \mathrm{~m}^{-1} \mathrm{~K}^{-1}$. Using the interval $90-140 \mathrm{~s}$ to extract $k_{\text {eff }}$ would have yielded a value of $0.115 \mathrm{~W} \mathrm{~m}^{-1} \mathrm{~K}^{-1}$. Choosing the adequate part of the plot to extract the correct thermal conductivity value is thus critical.

In order to develop an algorithm capable of accurately and automatically extracting thermal conductivity values from heating curves, we first analyzed our data manually from the 2012-2013 and 2013-2014 winters. This was done visually by examining the linearity of the plot and selecting the best possible linear section of the plot. This proved to be very easy, as a change of slope of about $5 \%$ is easily detected visually. In all cases, convection was easy to detect. In the absence of convection, a large time interval from 20 or $30 \mathrm{~s}$ to over $100 \mathrm{~s}$, was often found to have a very good visual linearity. This produced a set of reliable values against which to compare those obtained by our algorithm. The main con-
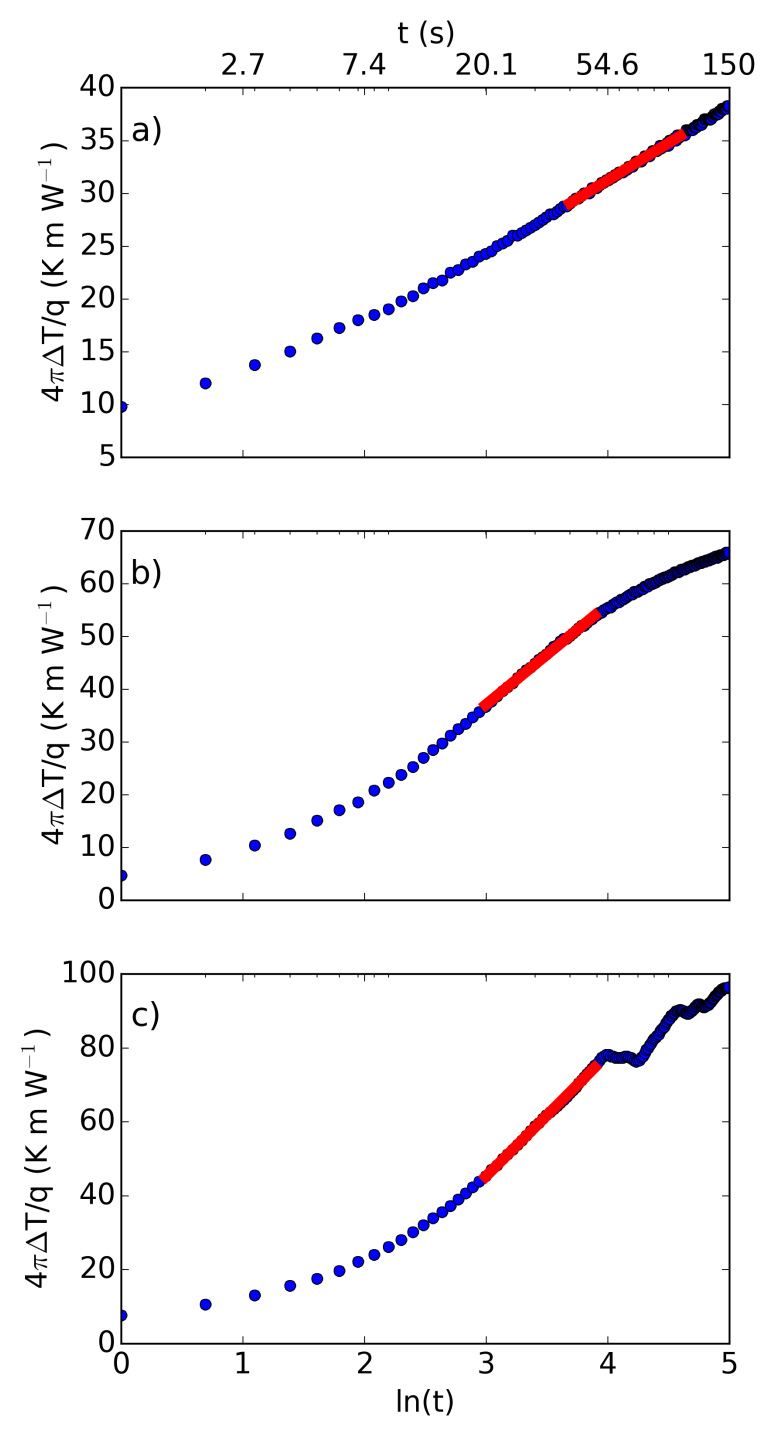

Figure 2. Heating plots obtained with the needle probes of Fig. 1. Red lines show the fit using the selected time range. (a) Heating plot obtained on 22 February 2013 with the NP at a height of 44 $\mathrm{cm}$. After an initial period of less than $20 \mathrm{~s}$ when steady state does not apply, the plot is linear. Time range used: 40-100 s. (b) Plot of 22 February 2013 with the NP at $34 \mathrm{~cm}$. The lower slope at long heating times is indicative of convection. Time range used: $20-50 \mathrm{~s}$. (c) Plot of 5 April 2013 with the needle probe at $14 \mathrm{~cm}$. $k_{\text {eff }}$ was $0.037 \mathrm{~W} \mathrm{~m}^{-1} \mathrm{~K}^{-1}$ and $\Delta T_{\max }$ was $3.5^{\circ} \mathrm{C}$, triggering intense and unstable convection. Time range used: $20-50 \mathrm{~s}$.

dition controlling the choice of the interval was the presence or the absence of convection. Thus, we tried to detect when convection occurred and to select the best time interval corresponding to both types of heating curves.

The analysis of 404 measurements showed that convection always occurred when the maximum heating, $\Delta T_{\max }$, at $100 \mathrm{~s}$ time and with a heating power of $0.4 \mathrm{~W} \mathrm{~m}^{-1}$, was greater than $1.18^{\circ} \mathrm{C}$, and never occurred when $\Delta T_{\max }$ was less than $1.07^{\circ} \mathrm{C}$. We obtained only two cases where convection took 
place for $\Delta T_{\max }<1.18^{\circ} \mathrm{C}$, with $\Delta T_{\max }$ values of 1.13 and $1.15^{\circ} \mathrm{C}$. We also found seven measurements without convection for $1.07 \leq \Delta T_{\max }<1.18^{\circ} \mathrm{C}$. To detect whether convection happened for cases within this $\Delta T_{\max }$ interval, we ran a routine to compare the $k_{\text {eff }}$ values yielded by two intervals, at short and at long heating times. If the value extracted from the long heating time was higher by $>5 \%$, then we considered that convection occurred, as observed in Fig. 2b. If not, we concluded there was no convection.

We then divided our heating curves into two classes, depending on their $\Delta T_{\max }$ values: the class without convection $\left(\Delta T_{\max }<1.07^{\circ} \mathrm{C}\right)$, and the class with convection $\left(\Delta T_{\max } \geq\right.$ $1.18^{\circ} \mathrm{C}$ ). When $\Delta T_{\max }$ is in-between, both behaviors could be found and the class of the heating curve was determined according to the additional procedure. For both classes, we tested various time intervals which we used to calculate $k_{\text {eff }}$. These values calculated automatically (hereafter "automatically calculated values") for selected intervals were then compared to the values, hereafter "manually calculated values", obtained using a manually selected time interval. Results are shown for both winters in Tables 1 and 2.

When convection was detected, the time interval giving the lowest root mean square deviation (RMSD) and the lowest algebraic error is $20-50 \mathrm{~s}$ for both years. We will then retain this interval when convection takes place. In the absence of convection, essentially all time intervals tested yielded values close to the manual ones, and selecting an interval is here a second order optimization. The optimal interval is $40-100 \mathrm{~s}$ in 2013-2014. In 2012-2103, the lowest RMSD came from the 50-110 s interval, and the lowest mean algebraic error from the 40-100 s one. However, in 2012-2013, the number of measurements without convection was only 34 , while it was 189 in 2013-2014. Moreover, results for the 40-100 s interval in 2012-2013 are not significantly different from those of the 50-110 s interval for RMSD, and give a better algebraic error. When convection is absent, we thus selected the 40-100 s time interval.

Finally, we applied a last check to ensure measurement quality. Despite the programming of the $-2{ }^{\circ} \mathrm{C}$ temperature threshold, we observed a few cases where snow was close to melting. Heating curves were then irregular, even showing decreases in temperature, presumably because of local melting. This only happened three times in spring, after the onset of snow melt, so we discarded these measurements anyway. We also encountered 10 cases of irregular heating curves with very large $\Delta T_{\max }\left(\geq 2.89^{\circ} \mathrm{C}\right)$, presumably due to an intense and unstable convection (Fig. 2c). Still, we successfully managed to extract the $k_{\text {eff }}$ values because the irregularities appeared after the 20-50 s time interval. This nevertheless showed us that poor quality heating curves could be obtained. To reject those, we set a threshold value on the quality of the linear fit. Thus, when the squared correlation coefficient $R^{2}$ was below 0.97 , the measurement was deemed unreliable and discarded.

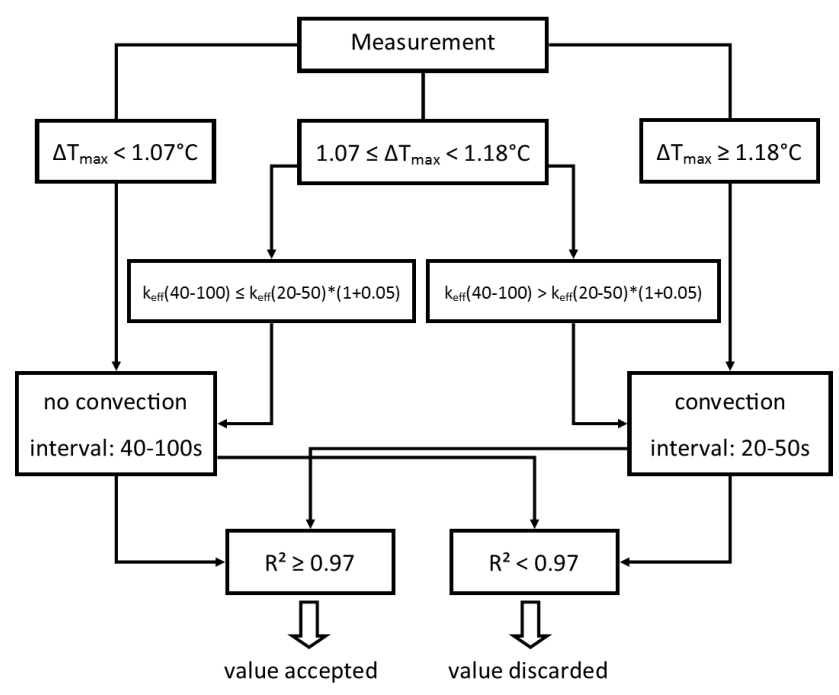

Figure 3. Schematic of the algorithm used to determine automatically the thermal conductivity value from the heating curves. $\Delta T_{\max }$ is the temperature rise measured after $100 \mathrm{~s}$ of heating.

From this analysis, we conclude that with a constant heating power of $0.4 \mathrm{~W} \mathrm{~m}^{-1}$, a heating time of $100 \mathrm{~s}$ is sufficient. Heating until $150 \mathrm{~s}$ does not lead to any gain in data quality and increases the risk of melting the snow, irreversibly modifying its structure. Our automatic treatment procedure is then as follows.

1. We determine the maximum heating of the measurement at $100 \mathrm{~s}, \Delta T_{\max }$ to detect whether convection was likely to have taken place. The convective threshold is $1.18^{\circ} \mathrm{C}$. Below $1.07^{\circ} \mathrm{C}$, convection is absent.

2. Based on the class of the measurement, a time interval is selected. We selected $40-100 \mathrm{~s}$ when the heating is below the $1.07^{\circ} \mathrm{C}$ threshold (no convection), and 20$50 \mathrm{~s}$ when it is above the $1.18^{\circ} \mathrm{C}$ threshold (convection).

3. For $\Delta T_{\max }$ between both thresholds, both behaviors are considered. Two $k_{\text {eff }}$ values from both time intervals are extracted and compared. If the value from the higher interval is greater than that from the lower interval by more than $5 \%$, then convection took place and the 20$50 \mathrm{~s}$ interval is selected. Otherwise, the interval 40 $100 \mathrm{~s}$ is used.

4. The $k_{\text {eff }}$ value obtained is kept only if the squared correlation coefficient is equal to or greater than 0.97 .

A schematic of the algorithm is shown in Fig. 3. In Tables 1 and 2, we also reported the maximum difference between the $k_{\text {eff }}$ values determined manually and automatically, and analyzed the cases where large errors were observed, in order to detect possible flaws in the algorithm. For the 2012-2013 winter, measurements without convection show a mean relative algebraic error of $0.44 \%$ for the interval $40-100 \mathrm{~s}$, with a 


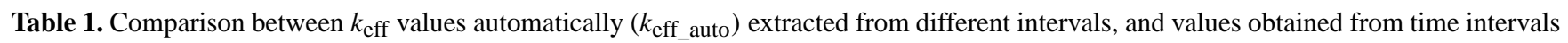
selected manually $\left(k_{\text {eff_man }}\right)$, for the 2012-2013 winter. Data for cases with and without convection are analyzed separately. RMSD is the root mean square deviation. Error is the mean relative algebraic error $2\left(k_{\text {eff_auto }}-k_{\text {eff_man }}\right) /\left(k_{\text {eff_auto }}+k_{\text {eff_man }}\right)$. The maximum error observed is also shown. Bold values correspond to the interval selected.

\begin{tabular}{lrrrrrr}
\hline $\begin{array}{l}N \text { total } \\
143\end{array}$ & \multicolumn{3}{c}{$\begin{array}{r}\text { without convection } \\
34\end{array}$} \\
\hline & $\begin{array}{r}\text { RMSD, \% } \\
\text { Interval, s }\end{array}$ & $\begin{array}{r}\text { Error, \% } \\
\text { no convection }\end{array}$ & $\begin{array}{r}\text { Error max, \% } \\
\text { no convection } \\
\text { no convection }\end{array}$ & $\begin{array}{r}\text { RMSD, \% } \\
\text { convection }\end{array}$ & $\begin{array}{r}\text { Error, \% } \\
\text { convection }\end{array}$ & $\begin{array}{r}\text { Error max, \% } \\
\text { convection }\end{array}$ \\
\hline $20-50$ & 3.52 & 3.18 & 7.64 & $\mathbf{3 . 7 4}$ & $\mathbf{3 . 3 3}$ & $\mathbf{- 6 . 1 2}$ \\
$30-60$ & 2.66 & 2.33 & 6.28 & 12.00 & 11.25 & 17.96 \\
$30-80$ & 2.08 & 1.65 & 4.50 & 18.98 & 17.90 & 40.11 \\
$40-90$ & 2.25 & 0.96 & 5.47 & 27.23 & 25.50 & 60.54 \\
$40-100$ & $\mathbf{1 . 8 5}$ & $\mathbf{0 . 4 4}$ & $-\mathbf{4 . 7 8}$ & 29.83 & 28.01 & 60.45 \\
$50-110$ & 1.69 & -0.46 & -5.21 & 37.15 & 34.59 & 71.31 \\
$60-120$ & 2.35 & -1.18 & -6.52 & 42.09 & 39.03 & 68.89 \\
$90-140$ & 3.48 & -1.72 & -8.02 & 53.66 & 49.08 & 97.37 \\
\hline
\end{tabular}

Table 2. Same as Table 1, for the 2013-2014 winter.

\begin{tabular}{|c|c|c|c|c|c|c|}
\hline \multirow{2}{*}{$\begin{array}{l}N \text { total } \\
261 \\
\text { Interval, } \mathrm{s}\end{array}$} & \multicolumn{3}{|c|}{$\begin{array}{c}N \text { without convection } \\
189\end{array}$} & \multicolumn{3}{|c|}{$\begin{array}{l}N \text { with convection } \\
72\end{array}$} \\
\hline & $\begin{array}{r}\text { RMSD, \% } \\
\text { no convection }\end{array}$ & $\begin{array}{r}\text { Error, \% } \\
\text { no convection }\end{array}$ & $\begin{array}{r}\text { Error max, \% } \\
\text { no convection }\end{array}$ & $\begin{array}{l}\text { RMSD, \% } \\
\text { convection }\end{array}$ & $\begin{array}{r}\text { Error, \% } \\
\text { convection }\end{array}$ & $\begin{array}{r}\text { Error max, \% } \\
\text { convection }\end{array}$ \\
\hline $20-50$ & 9.71 & 4.59 & 32.84 & 1.89 & -0.42 & 4.63 \\
\hline $30-60$ & 6.75 & 3.27 & 21.92 & 3.13 & 1.69 & 13.14 \\
\hline $30-80$ & 4.75 & 1.95 & 14.27 & 5.90 & 4.29 & 22.02 \\
\hline 40-90 & 3.78 & 0.47 & 12.18 & 8.94 & 7.48 & 26.68 \\
\hline $40-100$ & 3.65 & $-\mathbf{0 . 0 3}$ & 11.44 & 9.40 & 8.30 & 28.81 \\
\hline $50-110$ & 4.58 & -1.05 & 12.71 & 13.09 & 11.94 & 34.95 \\
\hline $60-120$ & 5.93 & -2.07 & -19.72 & 16.14 & 15.05 & 39.21 \\
\hline $90-140$ & 9.39 & -3.58 & 32.00 & 22.13 & 21.17 & 48.24 \\
\hline
\end{tabular}

largest algebraic error of $-4.78 \%$. For errors below $5 \%$, the calculation is deemed acceptable and no further investigation was made.

When convection was detected in 2012-2013, we obtained a mean error of $3.33 \%$ from the interval $20-50 \mathrm{~s}$. The highest errors, between 5 and $6.1 \%$, came from 11 measurements where convection took place early, before $45 \mathrm{~s}$. The linear regression applied between 20 and $50 \mathrm{~s}$ therefore leads to a slight overestimation of $k_{\text {eff }}$, giving a maximum error of $0.008 \mathrm{~W} \mathrm{~m}^{-1} \mathrm{~K}^{-1}$. In any case, it is likely that the early onset of convection makes a precise determination of $k_{\text {eff }}$ delicate, and the error in the manual determination is probably increased in this case. Taking the manual measurement as the correct reference is probably not ideal, and the value obtained in this case inevitably carries a larger uncertainty than usual. Thus, the interval 20-50 s remains the best compromise to obtain the lowest error for measurements with convection.

For the 2013-2014 winter, cases where convection was detected are fewer than the previous winter, and $k_{\text {eff }}$ extracted from the interval 20-50 s resulted in more accurate results, with a mean algebraic error of $-0.42 \%$ and a maximum quadratic error of $4.63 \%$.

In the absence of convection in 2013-2014, $k_{\text {eff }}$ values determined automatically from the time interval 40-100 s show a satisfactory mean relative algebraic error of $-0.03 \%$. The largest five errors, around $10 \%$, all came from the $24 \mathrm{~cm}$ needle. On those measurements, the slope of the heating curve was decreasing over time, which means that $k_{\text {eff }}$ is increasing probably because of heterogeneities in the snow. During our field work, we observed a lot of melt-freeze forms in the snowpack, especially at the height of this probe where we noticed several ice layers. These observations are consistent with the calculated $k_{\text {eff }}$ values, around $0.25 \mathrm{~W} \mathrm{~m}^{-1} \mathrm{~K}^{-1}$ (Sturm et al., 1997), and the shape of the curve reflects the heterogeneities observed. When the heating wave reaches a dense conductive layer, more heat is dissipated and heating is reduced. In these curved plots, it is difficult to select the most suitable interval, and the error largely reflects the arbitrary character of the manual determination. 
We also obtained 11 errors between 5 and $7 \%$ from the $14 \mathrm{~cm}$ needle. On these measurements, we found the opposite behavior than previously, with $k_{\text {eff }}$ decreasing after $50 \mathrm{~s}$. Given that the height of this probe corresponds to the basal depth hoar layer, we can attribute this change of slope to air-filled volumes in the snow. The absence of convection can be explained by the relatively high $k_{\text {eff }}$ values, around $0.18 \mathrm{~W} \mathrm{~m}^{-1} \mathrm{~K}^{-1}$, which reduces heating. These results are consistent with our field observations of a hard depth hoar layer at the same height.

In summary, using our algorithm with the time interval 20 $50 \mathrm{~s}$ when convection is detected, and 40-100 s otherwise, gives values within $5 \%$ of measured ones in $90.6 \%$ of cases. In $8.2 \%$ of cases, the difference is between 5 and $10 \%$. Errors above $10 \%$ were encountered only 5 times out of 404 values, and a physical explanation can be proposed in all cases. The most difficult determinations are probably for heterogeneous snow with melt-freeze structures. Based on this analysis of more than 400 heating curves, we therefore conclude that our algorithm is reliable with an overall RMSD of $3.27 \%$ and a maximum error of $11.4 \%$.

\section{Results}

Figure 4 shows the effective thermal conductivity values measured during the 2012-2013 winter. To facilitate discussion, we also show the evolution of air temperature, wind speed at $2 \mathrm{~m}$ height and of snowpack depth. Figure 5 shows data for the 2013-2014 winter. Thermal conductivity data does not start at the onset of the snow cover, because the snow temperature was too warm for the measurement to proceed. Figure 6 shows snow stratigraphies and density profiles in February of each year within about $50 \mathrm{~m}$ of our thermal conductivity NP location.

First of all, we must stress the fairly large spatial variation of snow properties. The ground surface was not flat and the snow redistribution by wind was important. This resulted in highly variable snowpack thickness. The dwarf birch cover was also highly variable. Within $100 \mathrm{~m}$ of our site, the ground could be covered with just white lichen (cladonia) or by dwarf birch bushes 20 to $80 \mathrm{~cm}$ high. Dwarf birch twigs absorb light and modify the local energy budget. All these variations resulted in variations in snow property at the meter scale, noticeable in the degree of melting, the amount, density and grain size of depth hoar, the thickness and hardness of wind slabs, etc. Such variations are usual in the Arctic and elsewhere, as illustrated in detail in e.g. Domine et al. (2012), see their Fig. 1. Strict correspondence between the data of Figs. 4 and 5 on the one hand, and Fig. 6 on the other hand should therefore not be sought.

Both winters had fairly similar meteorology regarding temperature and wind speed. Yet, in 2013-2014, there were much more extensive signs of melting in the snowpack. In February 2013, we observed only slight signs of melt-freeze
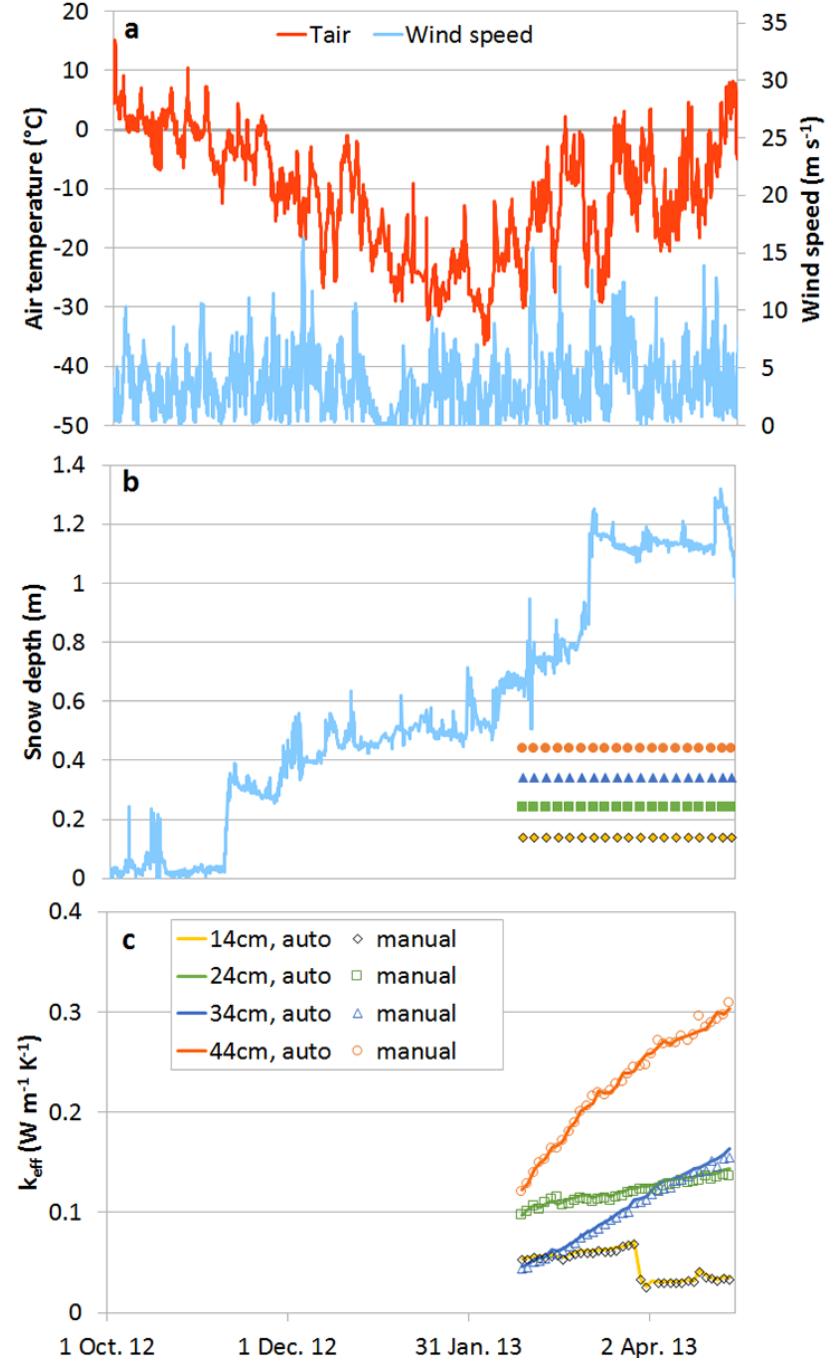

Figure 4. Meteorological and thermal conductivity data automatically recorded during the winter 2012-2013. (a) Air temperature and wind speed; (b) snow height and NPs height; (c) $k_{\text {eff }}$ time series. The snow gauge is about $6 \mathrm{~m}$ from the NPs, so that slight differences in snow heights at both spots are possible.

cycling in the snow, and the depth hoar was for the most part very soft and of low density $\left(<250 \mathrm{~kg} \mathrm{~m}^{-3}\right.$, sometimes even lower than 150). In February 2014, signs of melt-freeze cycling were extensive and the depth hoar was mixed with melt/refreeze clusters and was thus hard and of high density (> $250 \mathrm{~kg} \mathrm{~m}^{-3}$, sometimes even higher than 350) (Fig. 6).

Differences between both winters also show up when the $k_{\text {eff }}$ evolutions are examined. In 2012-2013, $k_{\text {eff }}$ values at 34 and $44 \mathrm{~cm}$ increased significantly and more than doubled. On the contrary, values at 14 and $24 \mathrm{~cm}$ showed only small increases, with the values at $14 \mathrm{~cm}$ even showing a sudden drop from 0.07 to $0.03 \mathrm{~W} \mathrm{~m}^{-1} \mathrm{~K}^{-1}$ between 28 and 30 March 2013. In 2013-2014, $k_{\text {eff }}$ values remained essentially constant, apart from three events: the initial increase 


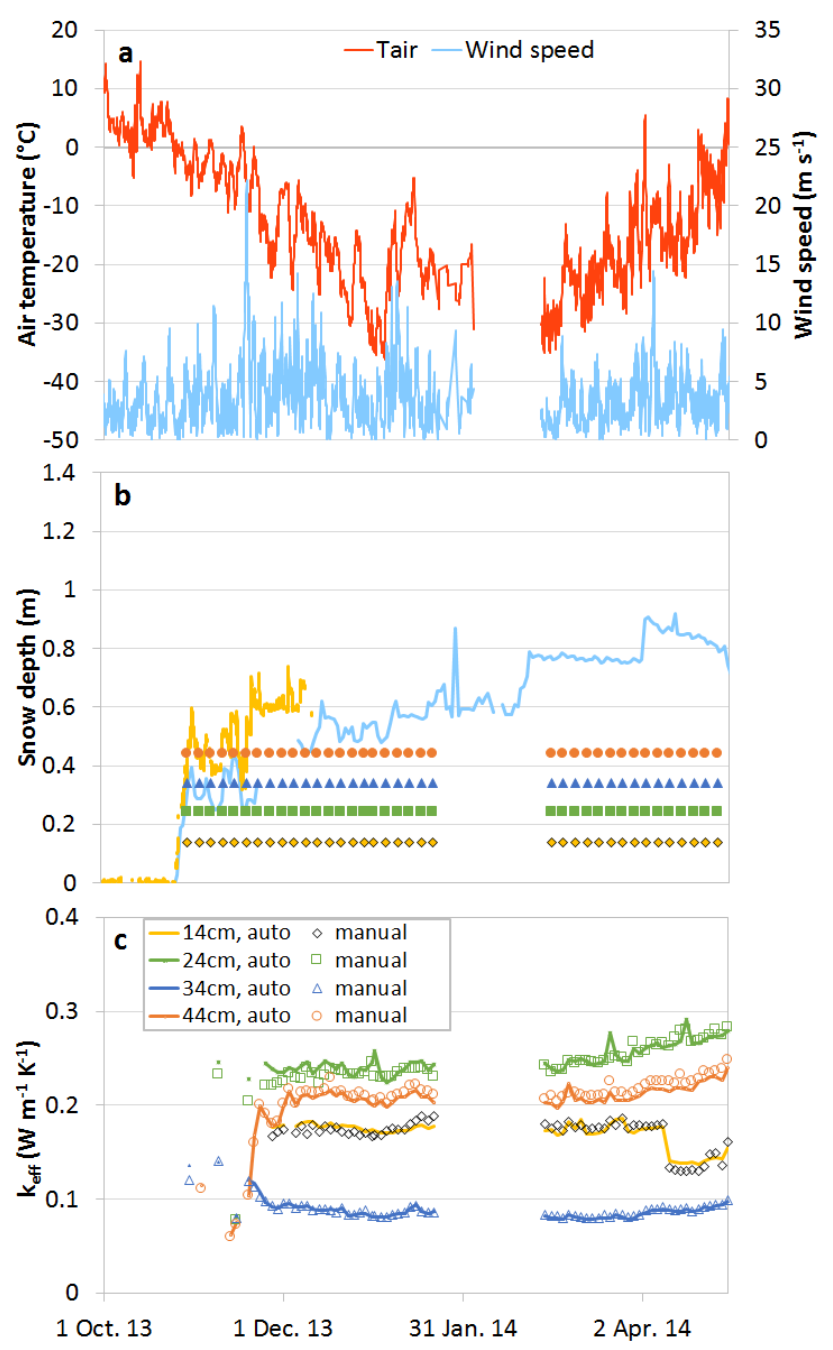

Figure 5. Meteorological and thermal conductivity data automatically recorded during the winter 2013-2014. A battery failure caused the loss of meteorological data between 3 and 28 February and of the thermal conductivity data between 23 January and 28 February. (a) Air temperature and wind speed; (b) snow height and NPs height. The snow gauge close to the NPs (yellow line) broke. We therefore show data from another snow gauge located about $20 \mathrm{~m}$ from the NPs. Because of topography, the snow heights differ at both spots; (c) $k_{\text {eff }}$ time series.

at $44 \mathrm{~cm}$, the initial decrease at $34 \mathrm{~cm}$, and again a sudden drop at $14 \mathrm{~cm}$ from 0.17 to $0.13 \mathrm{~W} \mathrm{~m}^{-1} \mathrm{~K}^{-1}$ between 9 and 11 April 2014.

\section{Discussion}

\subsection{Suitability of the method}

Methods currently used to determine snow thermal conductivity are the heated NP, the heat flux plate (HFP) and simulations based on microtomographic images (SIM) (Calonne

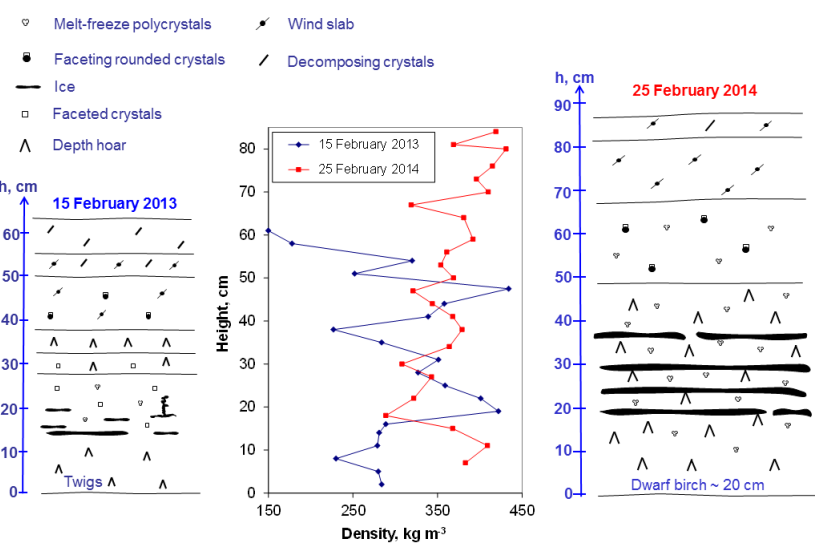

Figure 6. Stratigraphies and density profiles of the snow near our study site on 15 February 2013 (left) and 25 February 2014 (right). Snow crystal symbols are those detailed in Fierz et al. (2009). When ice layers were present, density measurements were difficult because the clean sampling of ice layers was delicate. It was then easy to underestimate snow density, possibly by as much as $20 \%$. Because of lateral variations, these stratigraphies are not necessarily identical to those present at the exact needle probe spot.

et al., 2011; Riche and Schneebeli, 2013). Briefly, for the HFP method, a known temperature gradient is established across a snow sample and the heat flux is measured. Equation (1) allows the determination of $k_{\text {eff }}$. For simulations, a 3-D microstructural image, typically with a resolution of $10 \mu \mathrm{m}$, is obtained for the snow sample. A finite element simulation is then performed, taking into account conduction through the ice and air. Latent heat fluxes are not considered in these simulations, because they are calculated to represent about $1 \%$ of heat transfer at $-16^{\circ} \mathrm{C}$ (Riche and Schneebeli, 2013). Both the HFP and SIM methods are not suited for the continuous monitoring of snow thermal conductivity in remote and inaccessible regions. Calonne et al. (2011) and Riche and Schneebeli (2013) have compared results from the three methods. Both studies conclude that the NP method has two weaknesses: (1) it does not take into account snow anisotropy; (2) it seems to systematically give values that are too low by about $35 \%$.

Snow is indeed anisotropic, as readily revealed for example by the cursory observation of columnar depth hoar. For the study of heat transfer through the snowpack, the relevant variable is the vertical thermal conductivity, $k_{z}$. In Arctic snow, NPs have to be inserted horizontally, because the heated region is $10 \mathrm{~cm}$ long, and this is very often much larger than the thickness of an Arctic snow layer, so that what is measured by a horizontal $\mathrm{NP}, k_{\mathrm{NP}, \mathrm{h}}$, is a mix between $k_{z}$ and the horizontal thermal conductivity $k_{\mathrm{h}}=k_{x}=k_{y}$ (Riche and Schneebeli, 2013):

$k_{\mathrm{NP}, \mathrm{h}}=\sqrt{k_{\mathrm{h}} k_{z}}$ 
Anisotropy can be quantified by the ratio $k_{z} / k_{\mathrm{h}}=\alpha$ (Riche and Schneebeli, 2013) so that we have

$k_{z}=\sqrt{\alpha} k_{\mathrm{NP}, \mathrm{h}}$.

Over half of the values of $\alpha$ are close to 1 (between 0.8 and 1.2) (Calonne et al., 2011; Riche and Schneebeli, 2013) so that measuring $k_{\mathrm{NP}, \mathrm{h}}$ to obtain $k_{z}$ will often only cause a small error due to anisotropy. However, over $90 \%$ of $\alpha$ values range between 0.7 to 1.45 (Calonne et al., 2011), and values as high as 2 have been observed, so that anisotropy on average creates an uncertainty of about $20 \%$ on $k_{z}$ from $k_{\mathrm{NP}, \mathrm{h}}$ measurements.

In available studies, NP gives systematically lower results than HPF and SIM. While HPF and SIM are not perfect and can have systematic errors, as detailed by Riche and Schneebeli (2013), these imperfections are probably not sufficient to explain the low values found by the NP method. Of particular interest is the observation that, while NP gives results similar to HFP in homogeneous isotropic materials such as polystyrene and wax, it gives lower values in granular materials such as salt grains and snow (Riche and Schneebeli, 2013). Thus the granular nature of the material may be related to the cause of the underestimation of $k_{\text {eff }}$ by NP. Riche and Schneebeli (2013) explore several possibilities to explain the underestimation. These are the following. (i) The high contact resistance - this would not apply in our case as the needle is not inserted each time and the medium perturbation is minimal. (ii) The heterogeneity in the temperature field from the measurement of the dielectric properties, it is known empirically that the radius of curvature of the electrode must be much larger than the snow grain diameter (Matzler, 1996). These conditions would not be fulfilled for snows such as depth hoar, as well as for the salt grains studied by Riche and Schneebeli (2013). (iii) The thermal field is too far from homogenous conditions for such a thin NP to apply the theory developed for transient methods (Blackwell, 1954; Matzler, 1996).

In any case, no definite understanding has been reached today. Calonne et al. (2011) analyzed their NP heating curve in a simple manner, using always the same 30-80 s time interval regardless of the curve shape. We reanalyzed NP data from Calonne et al. (2011) (both their one published value and other unpublished values that they supplied us with) with the algorithm of Fig. 3, and this on average increased their value by $10 \%$. Their published value in their Fig. 1 increased by $9 \%$, from 0.156 to $0.170 \mathrm{~W} \mathrm{~m}^{-1} \mathrm{~K}^{-1}$. We therefore come to the conclusion that, even though NP data are lower than SIM data, reanalyzed data are probably only about $10 \%$ lower than SIM data.

Riche and Schneebeli (2013) analyzed their NP heating curve using the constant 30-100 s time interval. Since they performed measurements both with a vertical and a horizontal needle, they could determine $k_{\mathrm{h}}$ and $k_{z}$ from their NP measurements and compared those with similar data obtained from SIM. Based on eight snow samples, they con- clude that NP data were "systematically lower by $10-35 \%$ " than SIM values. We did not re-evaluate the NP data of Riche and Schneebeli (2013). Based on our analysis of the data of Calonne et al. (2011) and on the data of Riche and Schneebeli (2013), we estimate that NP data, taking into account anisotropy, probably underestimates $k_{z}$ by about $20 \%$ on average.

In summary, errors in our monitoring data amount to a random error of $20 \%$ due to anisotropy if the snow type is not known, and a low systematic error that is on average $20 \%$. Additional random errors are that due to the NP method (5\%) and that due to our algorithm (3\%), leading to a total error of $29 \%$, deduced from the square root of the sum of the squares of all errors. Given that snow thermal conductivity varies in the range 0.025 to $0.7 \mathrm{~W} \mathrm{~m}^{-1} \mathrm{~K}^{-1}$ (Sturm et al., 1997), i.e a factor of almost 30 , the data obtained are still very useful, despite the errors. Corrections can be proposed to reduce the errors. To begin with, NP data can be increased by $20 \%$ to remove the systematic error and limit the uncertainty to its random component, $21 \%$. Second, corrections can be suggested for anisotropy. Lower Arctic snow layers are usually made up of depth hoar, with $k_{z}>k_{\mathrm{h}}$, while upper layers are usually made up of wind slabs with $k_{z}<k_{\mathrm{h}}$. Based on Eq. (5) and on a mean anisotropy of $20 \%$, our data at 14 and $24 \mathrm{~cm}$ could be increased by $20 \%$ and those at 34 and $44 \mathrm{~cm}$ decreased by $20 \%$. These tentative corrections can be refined when the difference between NP and SIM measurements are better understood. At the moment, the comparison is based on 2 studies totalling less than 10 measurements and little theoretical understanding of the processes, so there is room for a lot of improvements. Future detailed simulations of the snowpack energy balance may also produce a valuable comparison between observations and models, which may help reduce uncertainties. However, our current ability to model snow on shrub tundra is probably insufficient to reach the accuracy required for such comparisons.

\subsection{Thermal conductivity of snow in shrub tundra}

Our study site is a low-Arctic one, in shrub tundra near the tree line. Relevant climatic characteristics include fairly cold weather with temperatures as low as $-36{ }^{\circ} \mathrm{C}$ both years, above freezing episodes in autumn, a fairly low latitude that ensures significant insolation all winter (typically 50 to $150 \mathrm{~W} \mathrm{~m}^{-2}$ daily maximum, during the 120 days centered on the winter solstice), and the presence of shrubs that can act as radiation absorbers above and within the snow. To our knowledge, the time series of snow thermal conductivity presented here are the only ones available for shrub tundra. The conditions encountered here were significantly different from those in similar previous studies. Sturm and Johnson (1992) worked in interior Alaska on a spot with no erect vegetation. Winters there were colder than at our site, with no melting events. The thin snowpack, combined with the cold temperatures, generated extreme temperature gradients 


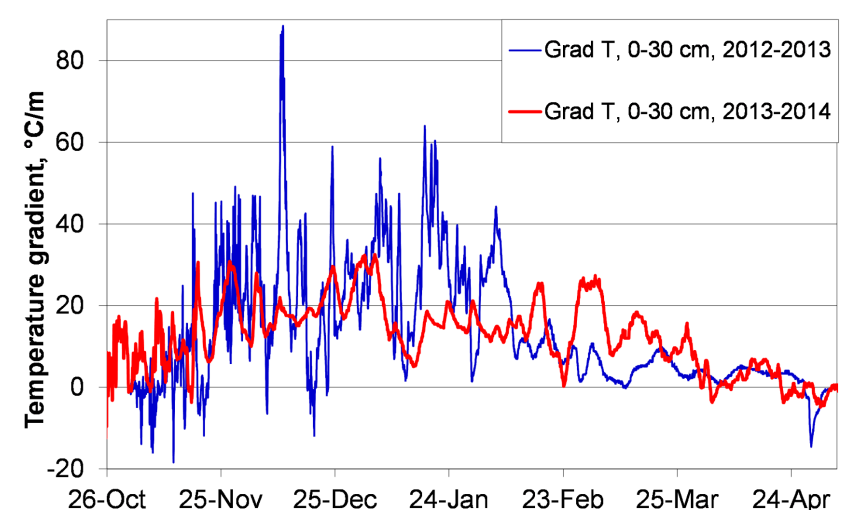

Figure 7. Temperature gradient in the snowpack in the bottom $30 \mathrm{~cm}$, calculated as $\left(T_{0 \mathrm{~cm}}-T_{30 \mathrm{~cm}}\right) / 0.3$, for both winters studied.

in the snow, reaching $300 \mathrm{~K} \mathrm{~m}^{-1}$, and almost all the snow cover transformed into depth hoar (Sturm and Benson, 1997). Morin et al. (2010) worked in an unvegetated high-Alpine area with high snow accumulation $(\sim 2 \mathrm{~m})$. Air temperatures were moderate, fluctuating mostly between 0 and $-15^{\circ} \mathrm{C}$, and signs of melting were not readily observed. Originalities of our site include the important occurrence of melting and the presence of shrubs with a dense network of twigs. We focus our discussion on both these aspects, and also investigate the difference in the evolution of $k_{\text {eff }}$ between both winters studied.

Our data suggest that both meteorological conditions and snow metamorphism contributed to the difference between both years. In 2012, continuous snow cover started on 8 November, and in 2013 on 26 October. Between the start of the permanent snow cover and 31 December, the average temperature was $-9.3{ }^{\circ} \mathrm{C}$ in 2012 and $-11.9^{\circ} \mathrm{C}$ in 2013 , which does not explain the melt signs difference in both years. There were more warm spells in the second year, which is more consistent with observations. In 2012-2013, the amount of air temperature above $0^{\circ} \mathrm{C}$ after permanent snow cover was $51^{\circ} \mathrm{C}$ hour until February, and in 20132014 , the value was $96^{\circ} \mathrm{C}$ hour. Of course, air temperature alone is insufficient to estimate the intensity of melting. Also relevant is the intensity of solar radiation. While in autumn 2012, incident solar radiation after the onset of permanent snow cover exceeded $200 \mathrm{~W} \mathrm{~m}^{-2}$ only once (on 18 November) it exceeded that value on 7 days in autumn 2013 , even reaching $336 \mathrm{~W} \mathrm{~m}^{-2}$ on 28 October, when the snowpack was about $25 \mathrm{~cm}$ high. Even though the air temperature only reached $-1.4^{\circ} \mathrm{C}$ on that day, light absorption by the snow, increased by the widespread presence of dwarf birch twigs, doubtless produced significant melting.

Furthermore, metamorphic conditions increased the difference between both years. Strong temperature gradient metamorphism can transform refrozen snow into depth hoar (Domine et al., 2009), therefore erasing the melting history. The thicker snow in 2013 , by reducing the temperature gra- dient, certainly slowed down transformation into depth hoar. Figure 7 shows the temperature gradient in the bottom $30 \mathrm{~cm}$ of the snowpack. Between the establishment of the snowpack and 20 February, the mean value was $22.5^{\circ} \mathrm{C} \mathrm{m}^{-1}$ in 2012 2013 and $15.6^{\circ} \mathrm{C} \mathrm{m}^{-1}$ in $2013-2014$. Thus the larger amount of melting and the lower temperature gradient in 2013-2014 combined to produce a snowpack with more remaining signs of melting in the middle of winter.

Only very few studies have been devoted to the timeevolution of snow thermal conductivity over extended time periods in natural environments (Morin et al., 2010; Sturm and Johnson, 1992), all dealing with the evolution of dry snow. Variables that play a role in this evolution include snow density and the temperature gradient in the snowpack. General observations in these studies are that in low density snow under high temperature gradient, metamorphism leads to depth hoar formation and $k_{\text {eff }}$ shows little variations and values usually remain low $\left(<0.1 \mathrm{~W} \mathrm{~m}^{-1} \mathrm{~K}^{-1}\right)$ to moderate $\left(<0.15 \mathrm{~W} \mathrm{~m}^{-1} \mathrm{~K}^{-1}\right)$. In higher density snow under low temperature gradient, metamorphism favors sintering and the strengthening of bonds between grains, leading to increases in $k_{\text {eff }}$ to values exceeding $0.2 \mathrm{~W} \mathrm{~m}^{-1} \mathrm{~K}^{-1}$. Laboratory experiments (Schneebeli and Sokratov, 2004; Calonne et al., 2014) confirm this trend.

For the first winter studied, $k_{\text {eff }}$ data start on 16 February 2013. Between that date and 29 April, the temperature gradient in the snow was low, with an average value of $4.45^{\circ} \mathrm{C} \mathrm{m}^{-1}$ between 0 and $30 \mathrm{~cm}$ (Fig. 7). Intense precipitation in March with snow height exceeding $120 \mathrm{~cm}$ (Fig. 4) led to the build-up of a strong overburden that certainly densified the lower snow layers. $k_{\text {eff }}$ values at 34 and $44 \mathrm{~cm}$ then increased rapidly, due to efficient sintering under these conditions. Layers at 14 and $24 \mathrm{~cm}$ showed a less marked increase, probably because the birch twig network prevented compaction, so that sintering in snow of lower density was less efficient. The sudden drop in $k_{\text {eff }}$ at $14 \mathrm{~cm}$ is interesting. We observed that very low density depth hoar $\left(<140 \mathrm{~kg} \mathrm{~m}^{-3}\right)$ could develop in the lower part of the birch shrubs, and this depth hoar often collapsed at the slightest contact. In places, voids were even present, presumably due to earlier spontaneous collapse. Our hypothesis is that between 28 and 30 March 2013, the depth hoar spontaneously collapsed and the NP found itself in a void within the depth hoar. Indeed,

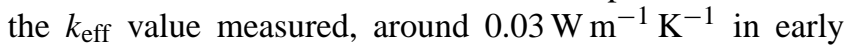
April, is close to the value of air, 0.023 . Our value is slightly higher, possibly because some ice crystals may have formed on the needle during depth hoar formation, as the strong upward water vapor flux could have led to condensation on the needle. Indeed, during laboratory experiments, such crystal formation was observed (N. Calonne, personal communication, 2015).

In 2013-2014, an initial rapid increase is observed at $44 \mathrm{~cm}$ between 17 and 19 November, and an initial slower decrease is observed at $34 \mathrm{~cm}$ between 9 and 25 November. The $44 \mathrm{~cm}$ increase is due to a wind storm between 17 and 
19 November, with wind speed exceeding $22 \mathrm{~m} \mathrm{~s}^{-1}$ at $2 \mathrm{~m}$, which transformed recent precipitation into a wind slab. We propose that the $34 \mathrm{~cm}$ decrease is due to the transformation of the snow layer into faceted crystals and possibly depth hoar. Similar decreases have been observed by Sturm and Johnson (1992) and Morin et al. (2010), who interpreted it likewise.

Beside these initial processes and the April drop at $14 \mathrm{~cm}$, $k_{\text {eff }}$ values show little variations. Temperature gradients in the snow were overall lower than the previous winter, but values were more regular in particular at the end of the season. Values exceeding $20^{\circ} \mathrm{C} \mathrm{m}^{-1}$ were observed until 5 March (compared to 9 February the previous winter) and the average gradient at $0-30 \mathrm{~cm}$ height between 16 February and 29 April 2013 was $8.72^{\circ} \mathrm{C} \mathrm{m}^{-1}$ (Fig. 7). We hypothesize that the melt-freeze layers formed a rigid 3-D network that prevented densification despite snowpack overburden in late winter. Since density and thermal conductivity are highly correlated (Domine et al., 2011; Sturm et al., 1997; Yen, 1981), it is not surprising that the lack of densification led to an absence of increase in $k_{\text {eff }}$.

The sudden slight drop in $k_{\text {eff }}$ at $14 \mathrm{~cm}$ is puzzling. Given that post-drop values are around 0.13 , i.e. much larger than the air value, the complete collapse of the depth hoar cannot be invoked. We tentatively suggest that the snow structure was a mixture of depth hoar and melt-freeze crust, and the continuous weakening of this mixed structure during months of temperature gradient metamorphism led to its partial collapse. However, we are fully aware that additional observations are needed to test this suggestion.

\section{Conclusions}

This study demonstrates that NPs can be used in remote environments for the season-long monitoring of snow thermal conductivity. Of course, the NP method is not perfect, but even if in a worst case scenario, its error is $29 \%$, the data obtained are still of great interest, given the range of variation of snow $k_{\text {eff }}$, and also given the fact that we knew nothing about the evolution of $k_{\text {eff }}$ in low-Arctic shrub tundra, and no data were available on the time-evolution of $k_{\text {eff }}$ of refrozen snow.

Noteworthy observations include the impact of dense shrubs on snow structure. Shrubs increase light absorption, and we postulated that this contributed to the significant melting in autumn 2013. This had a considerable effect on snow structure and on the evolution of $k_{\text {eff. }}$ The other important effect of shrubs is to prevent compaction. This is readily observed at $14 \mathrm{~cm}$ in Fig. 4, where the increase in $k_{\text {eff }}$ is moderate. This lack of compaction, combined with the upward loss of mass due to the temperature gradient, led to the postulated snow collapse in late March 2013. Also in winter 2013, the increase in $k_{\text {eff }}$ at $24 \mathrm{~cm}$ is considerably less than at 34 and $44 \mathrm{~cm}$, and we interpret this also as an effect of the shrubs. Finally, melt-freeze episodes are also observed to limit snow compaction (and therefore increases in $k_{\text {eff }}$ ) by forming a rigid network of melt-freeze clusters.

Further exploitation of these data will include their use for the adaptation of snow physics models to shrub tundra. Improved simulations of the snow and soil energy budgets may help improve our understanding of the errors in the NP measurement of snow $k_{\text {eff. }}$ However, for snow model standards, a $29 \%$ uncertainty on $k_{\text {eff }}$ is not large, and reducing it will require a very detailed description of the effect of shrubs on radiation and on snow compaction and metamorphism. These aspects are often overlooked by snow models today. The interest for such future developments is high, as for example this will lead to an improved ability to simulate the thermal regime of the ground and the fate of permafrost.

Acknowledgements. This work was supported by the French Polar Institute (IPEV) through grant 1042 to F. Domine and by NSERC through the discovery grant program. We thank Neige Calonne and Frédéric Flin for kindly making their data available to us. CNRM-GAME/CEN and LGGE are part of LabEx OSUG@2020.

Edited by: M. Schneebeli

\section{References}

Blackwell, J. H.: A transient-flow method for determination of thermal constants of insulating materials in bulk .1. Theory, J. Appl. Phys., 25, 137-144, 1954.

Calonne, N., Flin, F., Geindreau, C., Lesaffre, B., and Rolland du Roscoat, S.: Study of a temperature gradient metamorphism of snow from 3-D images: time evolution of microstructures, physical properties and their associated anisotropy, The Cryosphere, 8, 2255-2274, doi:10.5194/tc-8-2255-2014, 2014.

Calonne, N., Flin, F., Morin, S., Lesaffre, B., du Roscoat, S. R., and Geindreau, C.: Numerical and experimental investigations of the effective thermal conductivity of snow, Geophys. Res. Lett., 38, L23501, doi:10.1029/2011g1049234, 2011.

Conger, S. M. and McClung, D. M.: Comparison of density cutters for snow profile observations, J. Glaciol., 55, 163-169, 2009.

Domine, F., Taillandier, A.-S., Cabanes, A., Douglas, T. A., and Sturm, M.: Three examples where the specific surface area of snow increased over time, The Cryosphere, 3, 31-39, doi:10.5194/tc-3-31-2009, 2009.

Domine, F., Bock, J., Morin, S., and Giraud, G.: Linking the effective thermal conductivity of snow to its shear strength and its density, J. Geophys. Res., 116, F04027, doi:10.1029/2011JF002000, 2011.

Domine, F., Gallet, J.-C., Bock, J., and Morin, S.: Structure, specific surface area and thermal conductivity of the snowpack around Barrow, Alaska, J. Geophys. Res., 117, D00R14, doi:10.1029/2011jd016647, 2012.

Ekici, A., Chadburn, S., Chaudhary, N., Hajdu, L. H., Marmy, A., Peng, S., Boike, J., Burke, E., Friend, A. D., Hauck, C., Krinner, G., Langer, M., Miller, P. A., and Beer, C.: Site-level model intercomparison of high latitude and high altitude soil thermal 
dynamics in tundra and barren landscapes, The Cryosphere Discuss., 8, 4959-5013, doi:10.5194/tcd-8-4959-2014, 2014.

Fierz, C., Armstrong, R. L., Durand, Y., Etchevers, P., Greene, E., McClung, D. M., Nishimura, K., Satyawali, P. K., and Sokratov, S. A.: The International classification for seasonal snow on the ground UNESCO-IHP, ParisIACS Contribution No 1, 80 pp., 2009.

Gouttevin, I., Menegoz, M., Dominé, F., Krinner, G., Koven, C., Ciais, P., Tarnocai, C., and Boike, J.: How the insulating properties of snow affect soil carbon distribution in the continental pan-Arctic area, J. Geophys. Res., 117, G02020, doi:10.1029/2011jg001916, 2012.

Koven, C. D., Ringeval, B., Friedlingstein, P., Ciais, P., Cadule, P., Khvorostyanov, D., Krinner, G., and Tarnocai, C.: Permafrost carbon-climate feedbacks accelerate global warming, P. Natl. Acad. Sci. USA, 108, 14769-14774, 2011.

Liston, G. E., McFadden, J. P., Sturm, M., and Pielke, R. A.: Modelled changes in arctic tundra snow, energy and moisture fluxes due to increased shrubs, Global Change Biol., 8, 17-32, 2002.

Matzler, C.: Microwave permittivity of dry snow, IEEE Trans. Geosci. Remote Sens., 34, 573-581, 1996.

Morin, S., Domine, F., Arnaud, L., and Picard, G.: In-situ measurement of the effective thermal conductivity of snow, Cold Reg. Sci. Technol., 64, 73-80, 2010.

Payette, S., Fortin, M.-J., and Gamache, I.: The subarctic foresttundra: The structure of a biome in a changing climate, BioSci., 51, 709-718, 2001.

Riche, F. and Schneebeli, M.: Microstructural change around a needle probe to measure thermal conductivity of snow, J. Glaciol., 56, 871-876, 2010.

Riche, F. and Schneebeli, M.: Thermal conductivity of snow measured by three independent methods and anisotropy considerations, The Cryosphere, 7, 217-227, doi:10.5194/tc-7-217-2013, 2013.

Saccone, P., Morin, S., Baptist, F., Bonneville, J.-M., Colace, M.P., Domine, F., Faure, M., Geremia, R., Lochet, J., Poly, F., Lavorel, S., and Clément, J.-C.: The effects of snowpack properties and plant strategies on litter decomposition during winter in subalpine meadows, Plant Soil, 363, 215-229, 2013.
Schneebeli, M. and Sokratov, S. A.: Tomography of temperature gradient metamorphism of snow and associated changes in heat conductivity, Hydrol. Process., 18, 3655-3665, 2004.

Schuur, E. A. G., Bockheim, J., Canadell, J. G., Euskirchen, E., Field, C. B., Goryachkin, S. V., Hagemann, S., Kuhry, P., Lafleur, P. M., Lee, H., Mazhitova, G., Nelson, F. E., Rinke, A., Romanovsky, V. E., Shiklomanov, N., Tarnocai, C., Venevsky, S., Vogel, J. G., and Zimov, S. A.: Vulnerability of permafrost carbon to climate change: Implications for the global carbon cycle, Bioscience, 58, 701-714, 2008.

Sturm, M. and Benson, C. S.: Vapor transport, grain growth and depth-hoar development in the subarctic snow, J. Glaciol., 43, 42-59, 1997.

Sturm, M. and Johnson, J. B.: Thermal-conductivity measurements of depth hoar, J. Geophys. Res.-Solid Earth, 97, 2129-2139, 1992.

Sturm, M., Holmgren, J., Konig, M., and Morris, K.: The thermal conductivity of seasonal snow, J. Glaciol., 43, 26-41, 1997.

Sturm, M., McFadden, J. P., Liston, G. E., Chapin, F. S., Racine, C. H., and Holmgren, J.: Snow-shrub interactions in Arctic tundra: A hypothesis with climatic implications, J. Climate, 14, 336344, 2001.

Sturm, M., Schimel, J., Michaelson, G., Welker, J. M., Oberbauer, S. F., Liston, G. E., Fahnestock, J., and Romanovsky, V. E.: Winter biological processes could help convert arctic tundra to shrubland, Bioscience, 55, 17-26, 2005.

Yen, Y.-C.: Review of thermal properties of snow, ice, and sea ice, United States Army Corps of Engineers, Hanover, N.H., USACRREL Report 81-10, 1-27 pp., 1981.

Zhang, T. J.: Influence of the seasonal snow cover on the ground thermal regime: An overview, Rev. Geophys., 43, RG4002, doi:10.1029/2004rg000157, 2005. 